\title{
Why children with inflammatory bowel disease are diagnosed at a younger age than their affected parent
}

\author{
J C W Lee, S Bridger, C McGregor, A J S Macpherson, J E Lennard Jones
}

\begin{abstract}
Background-Genetic anticipation has been proposed to explain observed age differences at diagnosis of Crohn's disease in affected parents and offspring.

Aims-To compare affected parent-child pairs with Crohn's disease and ulcerative colitis with a control group of non-familial patients with inflammatory bowel disease (IBD) in order to quantify whether ascertainment bias could account for this effect.

Methods-137 affected parent-child pairs from 96 families and 214 patients with sporadic IBD were studied. Age at onset of symptoms and diagnosis were ascertained by interview and disease confirmed from clinical records.
\end{abstract}

Results-Of the 137 affected parent-child pairs, 50 had Crohn's disease only, 51 had ulcerative colitis only, and in 36 , one had Crohn's disease and the other ulcerative colitis. The median age of parents at diagnosis was 17.5 years older, 16 years older, and 18 years older in the Crohn's disease, ulcerative colitis, and mixed disease families respectively $(p<0.001$ in each case). These observed age differences were compatible with those predicted from the regression lines of years of birth against age at diagnosis for the non-familial IBD patients. No evidence was found for an effect of parental sex on age at diagnosis or disease extent in offspring.

Conclusions-There was no evidence of genetic anticipation or genomic imprinting of age at diagnosis in this sample of IBD families. Ascertainment bias is responsible for the age differences at diagnosis between affected parents and children.

(Gut 1999;44:808-811)

Keywords: Crohn's disease; ulcerative colitis; familial; genetic anticipation

Department of Medicine, King's College School of Medicine and

Dentistry, London, UK

$S$ Bridger

C McGregor

A J S Macpherson

Correspondence to: Professor J E Lennard-Jones, 72 Cumberland Street, Woodbridge, Suffolk IP12 4AD, UK.

Accepted for publication 13 January 1999 is known that the biological mechanism behind other conditions showing anticipation is an expansion of trinucleotide repeat sequences within the responsible gene. ${ }^{17}$ Clearly, if genetic anticipation really happens in Crohn's disease, a search for trinucleotide expansion between generations would be valuable in defining genes that are responsible for the condition. ${ }^{18}$

It is certain that affected offspring have a significantly earlier age of disease onset than their affected parent, and may also have greater extent of disease. ${ }^{89}{ }^{19}$ One report also provided tentative support for genomic imprinting in that affected children of affected Crohn's disease fathers had more extensive disease than children of affected mothers. ${ }^{8}$ However, this finding is not universal. ${ }^{9}$

Although these features are consistent with anticipation, the original ${ }^{8}$ and subsequent publications ${ }^{9}$ proposing this mechanism were limited by small sample size (59 and 57 parent-child pairs respectively), selective examination of Crohn's kindreds, and incomplete analysis of the effects of bias. In particular, the major bias is probably the preferential ascertainment of parents with a later age at diagnosis. ${ }^{9}{ }^{20}$ No reported study has yet compared the effects of ascertainment bias in affected parent-child pairs with a control group.

The aim of this study was to look for evidence of anticipation and imprinting in a large cohort of parent-child pairs affected with different types of IBD, controlling for the effects of ascertainment bias with a control group of patients with non-familial disease.

Patients and methods

Ninety six families with a total of 137 affected parent-child pairs were identified by patient interview, postal survey of clinicians, search of hospital records, and membership of two UK national patient organisations. The 96 families studied comprised 31 affected with Crohn's disease only, 39 with ulcerative colitis, and 26 mixed families where cases of Crohn's disease and ulcerative colitis were present in the same family. In 56 families a parent and one child were affected, and in 35 a parent and two children had IBD, providing 56 and 70 parentchild pairs for analysis, respectively. Of the other five families, there were two in which three successive generations were affected, contributing five parent-child pairs to the

Abbreviations used in this paper: IBD, inflammatory bowel disease. 
Table 1 Median age at onset of symptoms and diagnosis in parents and children with inflammatory bowel disease

\begin{tabular}{lllll}
\hline & $\begin{array}{l}\text { Families with } \\
\text { CD only } \\
(n=50)\end{array}$ & $\begin{array}{l}\text { Families with } \\
\text { UC only } \\
(n=51)\end{array}$ & $\begin{array}{l}\text { Mixed disease } \\
\text { families } \\
(n=36)\end{array}$ & $\begin{array}{l}\text { All } \\
\text { families } \\
(n=137)\end{array}$ \\
\hline $\begin{array}{l}\text { Age at onset of symptoms (y) } \\
\quad \text { Parents }\end{array}$ & $31.5^{\star}$ & $40^{\star}$ & $37.5^{\star}$ & 38 \\
$\quad \begin{array}{l}\text { Children } \\
\text { Age at diagnosis (y) }\end{array}$ & 18.5 & 24 & 21.5 & 22 \\
$\quad$ Parents & $39^{\star}$ & $41^{\star}$ & $40^{\star}$ & 41 \\
$\quad \begin{array}{l}\text { Children } \\
\text { Predicted age at diagnosis (y) }\end{array}$ & 21.5 & 25 & 22 & 23 \\
$\quad \begin{array}{l}\text { Parents } \\
\quad \text { Children }\end{array}$ & $47.5^{\star}$ & $46^{\star}$ & $46^{\star}$ & 47 \\
$\begin{array}{l}\text { Time interval between onset of } \\
\text { symptoms and diagnosis (y) }\end{array}$ & 26 & 28.5 & 22.5 & 27 \\
$\quad \begin{array}{l}\text { Parents } \\
\text { Children }\end{array}$ & 7.5 & 1 & & \\
\hline
\end{tabular}

The predicted age of diagnosis was calculated using data obtained from the control group of patients with non-familial disease (see text for details).

${ }^{\star}$ Difference between parents and children, $\mathrm{p}<0.001$.

$\mathrm{CD}$, Crohn's disease; UC, ulcerative colitis.

study; in two families both parents and a child were affected and in these instances, the spouse who was diagnosed first was used in the analysis; and in one family a sister and brother with Crohn's disease had one and three children respectively providing four parent-child pairs for study. Thus a total of 137 parent-child pairs have been analysed within 96 families. Ninety one of the families were white (five with a Jewish ethnic origin), four were Asian, and one Afro-Caribbean.

A further 214 patients (113 with Crohn's disease and 101 with ulcerative colitis) with non-familial disease were recruited as a control group from the King's College Hospital IBD register. Clinical details for each of these patients were obtained by personal interview, information acquired from their clinicians and/or hospital records, and reviewing radiological films and histological slides on which the diagnosis of Crohn's disease and ulcerative colitis was based. From the interviews and

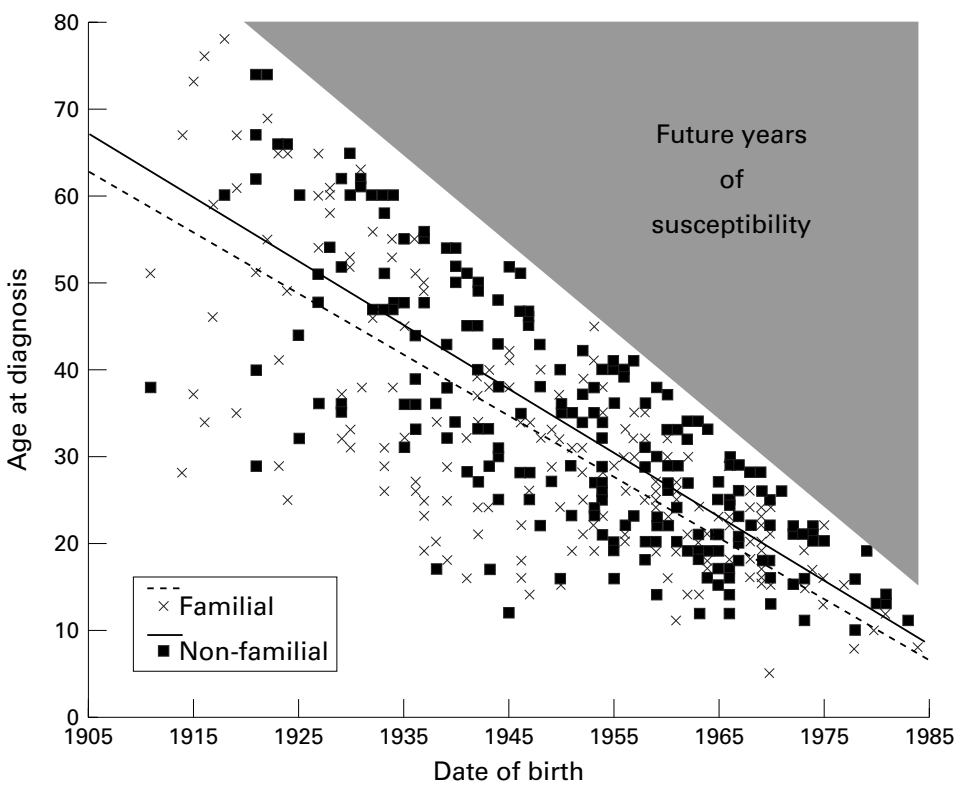

Figure 1 Correlation between age at diagnosis and calendar year of birth for patients with familial $(r=-0.77)$ and non-familial disease $(r=-0.78)$. Similar results are observed if the data for Crohn's disease and ulcerative colitis are plotted separately. Ascertainment bias is denoted by the shaded region encompassing the future years of susceptibility yet to be lived through. clinical records were noted the order in which family members were diagnosed with IBD, their year of birth, and their age at onset of symptoms and at diagnosis.

The sites of bowel involvement by Crohn's disease were classified as described by Bayless and colleagues ${ }^{21}$ : upper gastrointestinal tract (oesophagus, stomach, duodenum, and jejunum), ileum (includes caecum), right colon (ascending and transverse) and left colon (descending, sigmoid, and rectum), and perianal disease. The extent of disease was scored by the number of sites affected by Crohn's disease. For ulcerative colitis, the extent of colitis was defined as distal (disease involving the rectum with or without sigmoid colon involvement), left colon (rectum, sigmoid, and descending colon) and extensive (involvement proximal to the splenic flexure).

\section{STATISTICS}

Comparisons between generations for age at onset of disease and at diagnosis were analysed by the Mann-Whitney test. The relation between age at diagnosis and year of birth was assessed by regression analysis and Pearson's coefficient of correlation. A predicted age of diagnosis as determined by year of birth for affected parents and offspring was derived from regression plots of patients with either non-familial Crohn's disease or ulcerative colitis. McNemar's test for matched pairs with Yates's continuity correction was applied to assess differences in maternal and paternal transmission of Crohn's disease in the parentchild pair families with mixed disease.

\section{Results}

CHILDREN ARE YOUNGER AT SYMPTOMATIC ONSET AND DIAGNOSIS THAN THEIR PARENTS

Parents in the whole series had a median age at onset of symptoms 16 years older, and a median age at diagnosis 18 years older than their affected offspring. Table 1 summarises these differences for each of the three types of family studied. In $89 \%$ of the parent-child pairs, the parent was older than the child at the time when each was diagnosed, with an age difference of 10 or more years in $72 \%, 76.5 \%$, and $64 \%$ of the Crohn's disease, ulcerative colitis, and mixed disease pairs respectively.

The median time interval between diagnosis of the parent and child was 12 years (range 1-34) for the Crohn's disease families, 7.5 years (range 1-25) for the ulcerative colitis families, and 17 years (range 1-34) for the mixed disease families. A time span of five or more years separated the diagnosis of the two generations in $71 \%$ of the parent-child pairs, and in $56 \%$ this was more than 10 years.

\section{APPARENT ANTICIPATION CAN BE EXPLAINED BY} ASCERTAINMENT BIAS

Figure 1 represents the effect of ascertainment bias in the inverse correlation between age at diagnosis and calendar year of birth. When studied in 1998, anybody born in 1930 must be aged 68 or less and have been diagnosed under this age. The dramatic decline in age at diagnosis is therefore dictated by subtraction 
Table 2 Extent of disease for parent-child pairs in families affected with Crohn's disease or ulcerative colitis only

\begin{tabular}{lcll}
\hline & $\begin{array}{l}\text { Parent has } \\
\text { greater extent }\end{array}$ & $\begin{array}{l}\text { Child has } \\
\text { greater extent }\end{array}$ & $\begin{array}{l}\text { Same extent for both } \\
\text { parent and child }\end{array}$ \\
\hline Crohn's disease families $(\mathrm{n}=46)$ & $15(32.5 \%)$ & $14(30.5 \%)$ & $17(37 \%)$ \\
Ulcerative colitis families $(\mathrm{n}=40)$ & $9(22.5 \%)$ & $15(37.5 \%)$ & $16(40 \%)$ \\
\hline
\end{tabular}

and not by subtle year of birth effects. The magnitude of the effects of ascertainment bias were quantitated for the affected parent-child pairs by reference to the mean regression lines for the patients with non-familial disease. This clearly showed that the major determinant of difference in age at diagnosis between parents and offspring was their respective years of birth rather than their familial history of disease. No differences were noted between the gradients or the degrees of correlation of the regression plots for the familial and non-familial patients with either Crohn's disease or ulcerative colitis. Furthermore, the predicted age of diagnosis differences between the affected parent-child pairs were actually greater, although not significantly so, than the actual differences observed (see table 1).

COMPARISON OF DISEASE EXTENT IN

PARENT-CHILD PAIRS

Table 2 shows the extent of disease involvement in those Crohn's disease and ulcerative colitis families in whom this information was available (46/50 Crohn's disease pairs and $40 / 51$ ulcerative colitis pairs). No differences were noted in the extent of Crohn's disease in either parents or their children, but the extent of ulcerative colitis showed a slight but non-significant trend for greater extent among offspring.

\section{IMPRINTING}

Genomic imprinting can be associated with genetic anticipation and is observed if affected offspring display different phenotypic effects of genes carried on maternally derived as opposed to paternally derived chromosomes.

The differences in age at diagnosis between parents and children were similar in both offspring of affected fathers and mothers: mean 20.2 and 18.8 years respectively $(p=0.52)$. Parental sex did not affect disease extent in either the Crohn's disease or ulcerative colitis families. However, in the 36 families in which the diagnosis was discordant between the parent and offspring, an excess of ulcerative colitis parents with Crohn's disease affected children was observed. When this analysis was carried out separately for affected mothers and fathers, a small but significant difference was noted in the paternal transmission of Crohn's disease (table 3).

Table 3 Differences between maternal and paternal transmission of Crohn's disease in the mixed disease families

\begin{tabular}{llll}
\hline Mixed disease families $(n=36)$ & All parents & Affected fathers & Affected mothers \\
\hline Parent with UC, child with CD & 26 & 13 & 13 \\
Parent with CD, child with UC & 10 & 3 & 7 \\
Odds ratio (95\% confidence limits) & $2.6(1.2-6.0)$ & $4.3(1.2-23.7)$ & $1.86(0.7-5.5)$ \\
p Value & 0.0124 & 0.024 & 0.26 \\
\hline
\end{tabular}

CD, Crohn's disease; UC, ulcerative colitis.

\section{Discussion}

This is the largest study investigating age differences at diagnosis between affected parent-child pairs with inflammatory bowel disease. It is also the first study to examine families with both Crohn's disease and ulcerative colitis, and to use a control group of patients with non-familial disease. The major finding, that the median age at diagnosis for parents is significantly older than their children by $17.5,16$, and 18 years for the Crohn's disease, ulcerative colitis, and mixed disease families, is in agreement with all previous studies which have examined the ages of successive generations affected with IBD. ${ }^{8} 192223$ This has been suggested as evidence in favour of genetic anticipation in recent publications. However, this suggestion takes no account of the inherent bias within the parent-child study design. Ascertainment (patients in different generations are not interviewed at the same age, resulting in a greater chance of finding a later age of onset in the older generation), selection (less recruitment of patients with an earlier age of onset and reduced fertility), and lead time (time interval between onset of symptoms and diagnosis is shorter in the later generations affected), are all possible important observational biases. When compared with patients with non-familial disease, it is clear that the major determinant of difference in age at diagnosis between parents and offspring was their respective years of birth rather than their familial history of disease. In fact, the predicted age differences were actually greater than those observed.

An intriguing possibility to account for the age difference at diagnosis between the parents and children is that an environmental cohort effect has occurred during this century. It can be argued that the parents with IBD in the present study were born between the years 1911 and 1956, whereas their affected children were born during the period 1937-1984. A causal environmental factor introduced, or increasing its effect, towards the middle years of the twentieth century, would first affect many of the parents in early adult life whereas most of the children would be exposed from infancy. In this circumstance parents born early in the century would tend to develop IBD at a later stage in their life than their children. This possible explanation of the age difference at diagnosis between affected parents and children seems unlikely as the differences observed can be entirely accounted for by ascertainment bias.

Additional evidence against anticipation was provided by the observation that there were no significant differences between disease extent in either the Crohn's disease or ulcerative colitis parent-child pairs. We also found no effects of parental sex on disease extent or age at diagnosis, suggesting that genomic imprinting is unlikely to be of major importance in those families with Crohn's disease or ulcerative colitis only. The small but significant sex difference in parental transmission of Crohn's disease in the families with mixed disease, needs to be interpreted with some caution as only 36 of these families were included in the analysis and 
the confidence limits for the effects of parental sex were correspondingly wide.

Certain theoretical considerations would also suggest that anticipation is unlikely to be of major mechanistic importance in the aetiology of IBD. It is known that the molecular basis for anticipation is the inheritance of nucleotide triplet repeats in the disease gene that progressively expand in number in successive generations, and to date, the only known clinical examples occur in monogenic neurological disorders such as Friedreich's ataxia and Huntington's disease. ${ }^{24}$ It is clear that Crohn's disease and ulcerative colitis have important environmental influences, and do not follow simple Mendelian modes of inheritance; genome scans in affected sib pair populations suggest polygenic involvement. ${ }^{4-7}$ It is difficult to reconcile this knowledge with our present molecular understanding of anticipation.

In summary, the present study has confirmed that there is a tendency for children to be younger than their parents at the time of diagnosis in families with IBD affecting successive generations. Our evidence suggests that ascertainment bias is the reason for this phenomenon and not genetic anticipation.

We thank the families for their participation, the assistance of their clinicians in the collection of data, Yueming $\mathrm{Li}$ for help with the statistical analysis, and the support of the National Association for Colitis and Crohn's Disease and the Crohn's Disease in Childhood Research Association.

1 Satsangi J, Jewell DP, Rosenberg WM, et al. Genetics of inflammatory bowel disease. Gut 1994;35:696-700.

2 Tysk C, Lindberg E, Järnerot G, et al. Ulcerative colitis and Crohn's disease in an unselected population of monozygotic and dizygotic twins. A study of heritability and the influence of smoking. Gut 1988;29:990-6.

3 Thompson NP, Driscoll R, Pounder RE, et al. Genetics versus environment in inflammatory bowel disease: results of a British twin study. BMF 1996;312:95-6.

4 Hugot JP, Laurent Puig P, Gower Rousseau C, et al. Mapping of a susceptibility locus for Crohn's disease on chromosome 16. Nature 1996;379:821-3.

5 Ohmen JD, Yang HY, Yamamoto KK, et al. Susceptibility locus for inflammatory bowel disease on chromosome 16 has a role in Crohn's disease, but not in ulcerative colitis. Hum Mol Genet 1996;5:1679-83.

6 Parkes M, Satsangi J, Lathrop GM, et al. Susceptibility loci in inflammatory bowel disease. Lancet 1996;348:1588.

7 Satsangi J, Parkes M, Louis E, et al. Two stage genome-wide search in inflammatory bowel disease provides evidence for susceptibility loci on chromosomes 3, 7 and 12. Nat Genet 1996;14:199-202.

8 Polito JM II, Rees RC, Childs B, et al. Preliminary evidence for genetic anticipation in Crohn's disease. Lancet 1996; 347:798-800

9 Grandbastien B, Peeters M, Franchimont D, et al. Anticipation in familial Crohn's disease. Gut 1998;42:170-4.

10 Hugot JP, Colombel JF, Belaiche J, et al. Date of birth in familial Crohn's disease suggests environmental factors [abstract]. Gastroenterology 1998;114:A3112.

11 Hampe J, Heymann K, Kruis W, et al. Anticipation in inflammatory bowel disease: a phenomenon caused by a cumulation of confounders [abstract]. Gastroenterology 1998;114:A3118.

12 Lee JCW, Lennard Jones JE. Age difference at diagnosis between parents and children with inflammatory bowel disease: genetic anticipation or a cohort effect [abstract]. Gastroenterology 1998;114:A3128.

13 Gurubhagavatula S, Gold L, LaBuda M, et al. Genetic anticipation in fifteen three generation families with inflammatory bowel disease [abstract]. Gastroenterology 1998;114:A3129.

14 Gulwani-Akolkar B, Heresbach D, Lesser M, et al. Anticipation in Crohn's disease may be influenced by the ethnicity of the transmitting parent [abstract]. Gastroenterology 1998; 114:A3131.

15 Fiocchi C. Inflammatory bowel disease: etiology and pathogenesis. Gastroenterology 1998;115:182-205.

16 Chutkan R, Wang R, Sternthal MB, et al. Age of onset and "genetic anticipation" in inflammatory bowel disease [abstract]. Gastroenterology 1997;112:A950.

17 Ashley CT Jr, Warrent ST. Trinucleotide repeat expansion and human disease. Ann Rev Genet 1995;29:703-28.

18 Carpenter NJ. Genetic anticipation: expanding tandem repeats. Neurol Clin 1994;12:683-97.

19 Satsangi J, Grootscholten C, Holt H, et al. Clinical patterns of familial inflammatory bowel disease. Gut 1996;38:73841

20 McInnis MG. Anticipation: an old idea in new genes. $A m \mathcal{F}$ Hum Genet 1996;59:973-9.

21 Bayless TM, Tokayer AZ, Polito JM II, et al. Crohn's disease: concordance for site and clinical type in affected family members-potential hereditary influences. Gastroenterology 1996;111:573-9.

22 Peeters $M$, Nevens H, Baert F, et al. Familial aggregation in Crohn's disease: increased age-adjusted risk and concordance in clinical characteristics. Gastroenterology 1996;111: 597-603.

23 Griffiths A, Harris K, Smith C, et al. Is there anticipation in familial Crohn's disease [abstract]? Gastroenterology 1997; 112:A985.

24 Rosenberg RN. DNA triplet repeats and neurologic disease. N Engl F Med 1996;335:1222-4. 